\title{
Potential of Sloped Solar Chimney for the Architectural Development of Sustainable Applied Technology Models for Passive Air Ventilation
}

\author{
Sugini $^{1 *}$, Etik Mufida ${ }^{1}$, Risdiyono $^{1}$ \\ ${ }^{1}$ Architecture Department, Universitas Islam Indonesia, Yogyakarta, Indonesia \\ *sugini@uii.ac.id
}

Published: 30th April 2021

This paper presents the result of research section for solar chimney (SC) model innovation as a passive cooling strategy. The research is motivated by sustainability issues, especially on the issue of environmental degradation due to uncontrolled use of air conditioning in urban environments. The vertical SC (VSC) model has been tested by the author et al., 2018. Although in general the presence of VSC has a significant effect on room temperature but it turns out that the VSC column height, that is assumed as the main determinant of performance, does not significantly influence [1]. The character of sun altitude in Indonesia is believed to cause the vertical chimney to be ineffective. For this reason, this study tested the Sloped Solar Chimney (SSC) model. The purpose of this study is to test whether: (1) SSC is better than VSC; (2) the sloping chimney thickness and internal chimney height give a difference in SC performance. The SSC model consists of three components: (1) internal vertical chimney inlet; (2) External $30^{\circ}$ slope and (3) external outlets. The test model is made from galvalum. Overall, the research method was carried out in two stages, namely: (1) testing the simulative models by using a software based on empirical data on the context of the urban housing environment being sampled; (2) testing the models in the field. However, only the result of the first stage is presented in this paper. The location of the urban environment of dense housing used as a case study was Jogoyudan, Yogyakarta. The empirical data input consists of 3 groups of houses: on the banks of the river, in the middle of a dense housing and on the edge of a neighborhood road. The modeling software used is CFD analysis. The analysis uses a comparative test statistic with a confidence level of 5\%. From the results of the study it is found that SSC caused different thermal qualities in the test model room. The thickness of the sloping chimney also gives a difference in the thermal quality of space. However, this phase of the research has not been able to show significant effects due to the differences in height of the internal chimney.

Keywords: Sustainable applied technology; Sloped Solar Chimney inovation; Passive air ventilation 


\section{INTRODUCTION}

\section{Background}

The impact of climate change and global warming to the environmental degradation has become the world concern. One of the factors that causes the degradation is the consumption of fossil fuel. Indonesia ranked the second in the consumption of fossil fuel $(70 \%)$ after China (77\%). Whereas, Malaysia and Japan ranked the third and fourth. Thus, the energy conservation with the reduce of fossil fuel has become the top priority. One of the activities in human civilization that demands high consumption of energy such is building operation. The dominant aspect of energy consumption in building operation is air conditioner. Zhao et al (2017) concluded that the consumption of energy related with climate change increase in summer and winter. The number days where people using air conditioner become doubled during the time [2].

The high consumption of energy for cooling process can be reduced by developing passive approach technology. One of the developments in passive technology for building cooling operation is the advancement of solar chimney. Solar chimney is the technology that enhances the ventilation of building using buoyancy principles. In the buoyancy process, the airflow is expected to occur as the result of pressure difference caused by temperature change in distinctive height. Solar chimney has been developed by obtaining significant variables and parameters as well as Phase Change Material (PCM) that may prolong the duration of solar temperature to operate [3]. From the literature review, [3], it can be concluded that the use of solar chimney for building ventilation has the potential of diurnal and nocturnal ventilation. Moreover, other research on solar chimney in Shanghai concluded that the use of solar chimney will bring up to $14,5 \%$ efficiency of energy for building operation [4]

Globally, the studies on solar chimney have started to develop. However, in Indonesia, the research on such topic still needs to be explored. Indonesia has tropical climate with warm and humid temperature. One of special condition in Indonesia as the country that lays on the $0^{\circ}$ latitude is the high altitude of the sun. Similar to other developing countries, the process of urbanization in Indonesia continues to take place. The growing residence in urban area leads to the establishment of slum area in the cities. Along with the development of residential area, the use of air conditioner also increases. This eventually lead to the increase of energy consumption and air pollution such as refrigerant gas that may bring some impacts such as ozone depletion phenomenon. Yogyakarta as one of the cities in
Indonesia is also experiencing the growing number of housing in urban area with high economic activity. An area called Jogoyudan, becomes densely populated residential zone that supports the economic activity in cultural tourism area of Malioboro. For this research, the development of solar chimney with the setting of simple house in Jogoyudan urban is significant to be discussed. This topic becomes urgent considering the densely populated residence make it more difficult for houses to get driven ventilation. One of the solutions for the problem is the innovation of roof solar chimney. The researcher has developed vertical solar chimney with undergoing publication process on the issue. However, some research questions still need to be addressed. With high altitude of the sun, how to improve the performance of vertical solar chimney? One of the answers for this question is the innovation of sloped roof solar chimney.

A. The research objectives and research question Based on the explanation in the background, this research aims to address following questions:

Does sloped roof solar chimney have better performance than vertical roof solar chimney?

What geometrical factor will determine the performance of solar chimney on the sloped roof solar chimney?

This research measured the performance of solar chimney (SC) by observing the ability of SC in increasing air flow rate through buoyancy process. The performance is determined by the temperature produced in the upper room.

\section{THEORETICAL REVIEW: STATE OF THE ART}

Followings are literature review from some researches in the last 5 to 6 years in Indonesia and other countries.

\section{A. State of the Art outside Indonesia}

The first study is the research about design and models of energy with building with solar chimney that is integrated with the roof [5]. This research found that the solar chimney integrated with the roof can perform well without major change on the shape of the roof. This study was conducted numerically with CFD. It concluded that the natural convection in the wall of the chimney works well but the non-natural convection did not work well. There was difference of mass flow speed for less than 3.5 to 3 on the surface temperature. The difference was up to $60 \%$ higher on the heat transfer through the conduction of surface isolative solar chimney to the attic. This condition leads to the conclusion that the concept of roof solar chimney is potential as natural cooling system since it does not require the modification of roof shape. 
The second research is about the performance of solar chimney in the terrace house in Kuching, Malaysia [6]. This research examined the influence of height, width, and length of solar chimney tube towards the wind speed in the $36 \mathrm{~m} 3$ sized room. The model variation examination method is conducted with the CFD software simulation and towards the original model empirically. The findings indicated that the most significant dimension of solar chimney that influence the quality of room thermal is the room with the width of 0.6 to $1 \mathrm{~m}$ and length 1.5 to $2 \mathrm{~m}$. This study concluded that the solar chimney can increase the speed of the wind and the thermal comfort in the terrace house with the climate of Malaysia. This finding is essential to be the base of solar chimney research in Indonesia since the climate of Malaysia and Indonesia is very similar. In addition, the sun altitude is relatively the same. Both Indonesia and Malaysia have warm humid climate with high sun altitude.

The third research is about the application of perforated absorber plate in the roof solar chimney [7]. This research proposed for the modification of roof solar chimney by using perforated absorber plate. The threedimensional numeric simulation method is conducted to investigate the heat movement and the fluid flow in the roof solar chimney with difference gap width and slope angle. Absorber perforated plate divided the hollow space of the roof solar chimney into two. The slope angle used in this research is $30^{\circ}, 45^{\circ}$, and $60^{\circ}$ with the depth of $0.3 \mathrm{~m}, 0.4 \mathrm{~m}$, and $0.5 \mathrm{~m}$. This research has three main findings. Firstly, the maximum speed was obtained in the glass wall, absorber wall and absorber perforated plate from the optimized roof solar chimney. Secondly, the speed on the optimized roof solar chimney is higher than the traditional for different slope angle. Thirdly, the mass flow speed in the optimized roof solar chimney with the slope angle of $60^{\circ}$ and the depth of $0.5 \mathrm{~m}$ increased up to $35,0-39,7 \%$ compared to the traditional roof solar chimney. This research indicated that there is an opportunity for future innovation of roof solar chimney such as by putting perforated absorber plat in the roof solar chimney.

The fourth research is about passive solar cooling on the one story building with chiller absorber and the combination with solar chimney [8]. This research is another example of how to maximize the performance of solar chimney by putting absorber chiller component. The object of this research is one story building. The method of this research is theoretical simulation from the parameters of room temperature, relative humidity, and air changing per hour (ACH). This research also investigated the effect of surrounding environment, the demand of air conditioner, the dimension of solar chimney and the cooling channel in the room temperature. This research concluded that the use of three cooling plates in the channel resulted on lowest room temperature and decreased the consumption of electricity energy around $37 \%$ that is lower than the usage of inverter split air conditioner with the same cooling capacity.

The fifth research is about the effect of operational, geometrical, and material parameters of solar chimney outer cover towards the performance of solar chimney for natural ventilation [9]. From this research, it can be concluded that the increase of height, gap, and the width of the chimney will increase the air changing per hour $(\mathrm{ACH})$ flow. However, among those parameters, the chimney gap has a very significant effect towards ACH. Doubling the dimension of chimney will increase the mass flow velocity around $18 \%$ for the height, $78 \%$ for the gap, and $63 \%$ for the width. Therefore, although the parameters are a bit higher to increase the mass flow velocity, it becomes ineffective to be processed by considering the cost. The glass cover will increase the temperature in the chimney gap and absorber along with the increase of sun radiation. The use of concrete, gypsum board, and aluminium in the external wall construction (glass cover) will provide higher flow velocity.

The sixth study used experimental and numerical method on solar chimney for ventilation in the low energy building [4]. This research examined the performance of solar chimney in the full scale in a real building in eastern part of China. The performance was measured using theoretical calculation and numeric simulation. The mode of solar chimney has the length of $6.2 \mathrm{~m}$, width of $2.8 \mathrm{~m}$, and air gap of $0.35 \mathrm{~m}$. The findings showed that the air flow velocity reached $70.6 \mathrm{~m} 3 / \mathrm{jam} \sim 1887,6 \mathrm{~m} 3$ / hour in the day time of the examination. This value is lower than the theoretical calculation and numerical simulation. This research concluded that the solar chimney can be used to save energy up to $12.9 \%$ per year and 14.5 during the winter in Shanghai, China.

The study number seven is about the influence of inlet configuration on roof solar chimney [10]. The researchers conducted detail examination on the inlet configuration on solar chimney. The research obtained that inlet configuration with vertical inlet construction is the best configuration. However, horizontal configuration decreased the performance up to $84 \%$ compared to the vertical configuration.

The study number eight is about solar chimney with the phase change material (PCM) for building [3]. This 
research is an overview of researches using Computer Fluids Dynamics (CFD) and Global Energy Balance (GEB). Most of the case studies found that the optimum width of solar chimney channel is around 10 to 30 . To prevent recirculation in the exit of the chimney, the most recommended height is 2 to $3 \mathrm{~m}$. This study also concluded that solar chimney research with PCM materials is still limited. From the overview towards 14 researches, only 4 models used the transient model of CFD with PCM material. The PCM used for solar chimney is paraffin (paraffin candle and octadecana) considering the phase of temperature change. The solar chimney using PCM material proved that the use of paraffin extended the ventilation of the chimney for several hours before the sun set. Thus, further research needs to focus on extending the operational period of solar chimney trough massive wall or phase change material.

The ninth research is about the influence of height, slant, width, and air gap on slanted solar chimney in Egypt [11]. This research concluded that the width of the solar chimney is the most influential factor after slant and air gap. Whereas, solar height can be ignored. This research provided detail explanation that the use of the model showed significant match with the experiment result. This research also concluded the solar chimney with the height of $1.85 \mathrm{~m}$, width of $2.65 \mathrm{~m}$, slope angle of $75^{\circ}$, and air gap of $0,28 \mathrm{~m}$, can increase thermal comfort with higher intensity of sun for more than $500 \mathrm{~W} / \mathrm{m} 2$. The last study is about the potentials of solar chimney ventilation with partitioned air channel absorber in the climate of Mexico [12]. The context of climate in Mexico is similar to Indonesia that is warm and humid. The findings indicated that the average mass flow velocity in the coldest day is bigger than the warmest day in most of the month. The solar chimney with the absorber partition can produce around 7.9 and 11.4 Air Change per Hour $(\mathrm{ACH})$ for a bed room with a volume of volume $27 \mathrm{~m} 3$ and more than $3.5 \mathrm{ACH}$ for a classroom with a volume of $54 \mathrm{~m} 3$. In fact, those scores meet the standard and recommendation from ASHRAE.

\section{B. State of the Art in Indonesia}

From the literature review on the previous research in Indonesia on solar chimney, the researcher in this study found a research about passive application of solar induction ventilation for sustainable building in the equator line [13]. The method of this research is mathematic model to calculate the potentials of chimney ventilation in residential house. This model also uses artificial wind chimney to increase the movement of wind. From the simulation, it is found that every room experience the increase of $\mathrm{ACH}$ from 1-2 $\mathrm{ACH}$ to be 3
ACH. This condition caused the reduce of cooling burden (conditioned room) and improved thermal comfort for room without air conditioner. This reduce may potentially reduce the production of $\mathrm{CO} 2$. With the calculation based on the assumption of fan changing in the room to the system, then it is estimated that there will be dramatic decrease of $\mathrm{CO} 2$ production for about 1.800 $\mathrm{kg}$ and this will save about $176 \mathrm{US} \$$. From that research, it can be concluded that the research about solar chimney in Indonesia is not as advance as the research on the same topic in the other countries. Thus, this research will conduct a fundamental development gradually.

\section{METHODOLOGY}

The research was conducted in two steps. The first is collecting empirical data in the field. The location of this research is Jogoyudan, Yogyakarta, Indonesia which is an area with tropical climate where the weather is warm and humid with relatively high sun altitude. The figure ground condition of the housing complex is located on the street that is divided by river. There are three types of zones in the environment, namely zone for houses near the bank of river, zone for houses in the middle of residential area, and zone for houses on the side of the street. The houses in the three zones become the sample for weather measurement inside and outside the rooms. Afterward, after gathering the empirical data, the researcher input the data for performance simulation process using CFD. Physical model in scale were made as the base of modelling, as illustrated in Figure 1.

This research observed four models of sloped roof solar chimney. Model 1 has the thickness of air hollow space for $50 \mathrm{~cm}$ with the height of inlet for $200 \mathrm{~cm}$. Model 2 has the thickness of air hollow space for $25 \mathrm{~cm}$ with the height of inlet for $200 \mathrm{~cm}$. While model 3 has the thickness of air hollow space for $25 \mathrm{~cm}$ with the height of inlet for $100 \mathrm{~cm}$. Lastly, model 4 is vertical solar chimney with the thickness of air hollow space for 50 $\mathrm{cm}$. The slope of SRSC is $30^{\circ}$ as the common roof slope in the location using galvalume material. The simulation also used model of room without solar chimney as the control model.
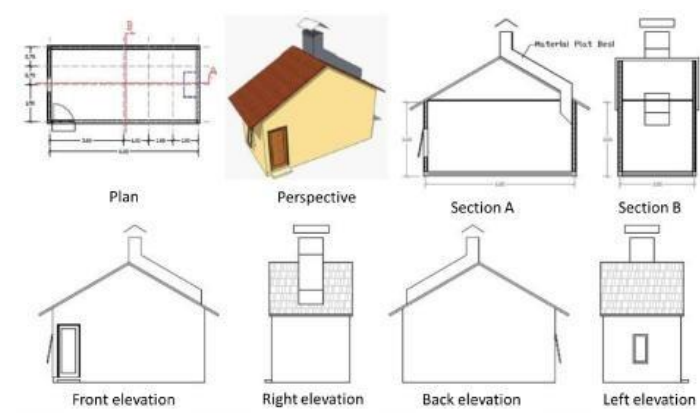

Figure 1: physical model in scale 


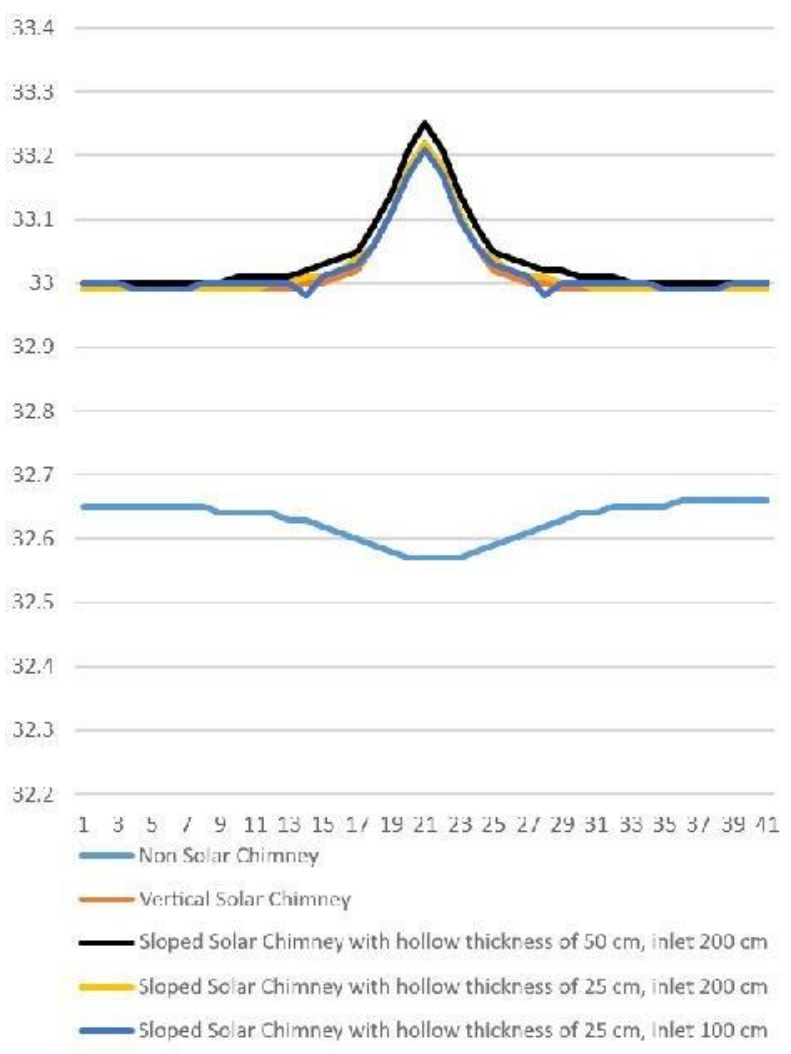

Figure 2: temperature the patter on room temperature in the room with no solar chimney (NSC), room with vertical solar chimney (VSC), and room with sloped solar chimney (SSC) with some variation of tube hollow thickness and different position of inlet

Based on physical model in scale, this research made digital modelling to be integrated with CFD model to measure the performance.

The next step is processing raw data from CFD quantitatively. From hundreds of numerical data in each point of the room, the average of 41 zones of room incision on the measurement point of $120 \mathrm{~m}$. The data calculation is summarized into 41 data. After data processing, this research conducted comparative analysis examination to identify the difference of thermal performance between rooms with SC both SRSC and VRSC with NSC.

\section{RESULT AND DISCUSSION}

The result from data abstraction process is illustrated in Figure 2. The illustration indicated a unique pattern. The temperature significantly increase in the zone in which $\mathrm{SC}$ is located. This unique pattern is also indicated in the research about the improvement of solar chimney application in two stories building with numerical approach. Although the result is not precisely the same, the result of data simulation showed the uniqueness of the pattern [14]. This proved that the innovation of SC both vertical and sloped will influence the pattern of room temperature.

The result of statistical research with reliability level of $5 \%$ indicated that there has been significant difference between room with solar chimney both VSC and SSC. This indicated that the technology of solar chimney as a passives strategy in room cooling is indeed potential. This is in line with the result of empirical examination in the terrace house in Kuching, Malaysia [6], and also in other research [5], [9], [4].

The result of comparative study on the thermal performance between rooms with VSC and SSC with the hollow space of $50 \mathrm{~cm}$ and $25 \mathrm{~cm}$ and height of inlet of $100 \mathrm{~cm}$ and $200 \mathrm{~cm}$ indicated significant difference. SSC has better performance as compared to VSC. Diagrammatically, the comparison of VSC and SSC performance can be seen in Figure 3. 


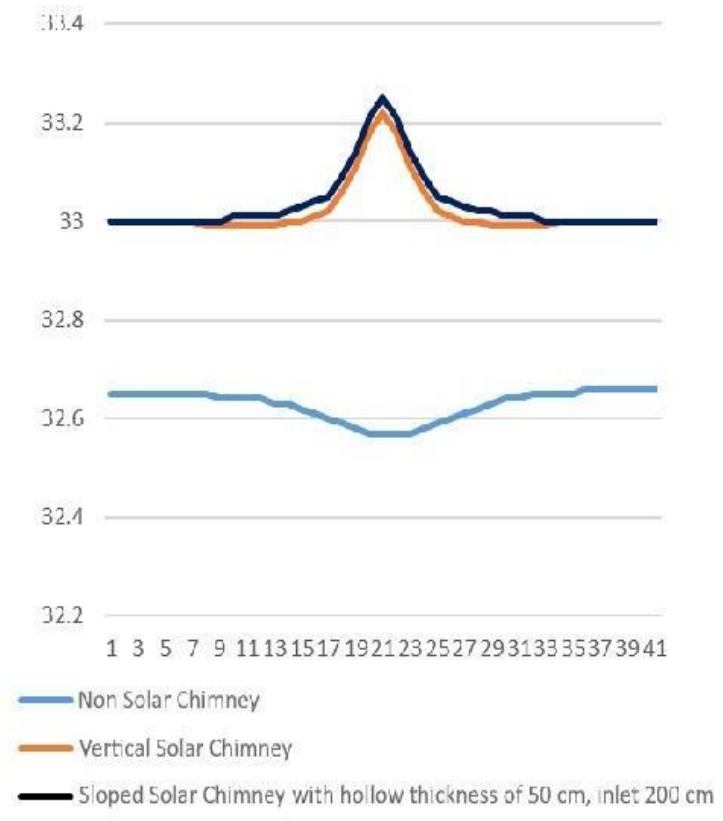

Figure 3: the comparison of average temperature in rooms with NSC, VSC, and SSC in the 41 zones

This result is consistent with the other research from Egypt [11]. As concluded in the research that after the width dimension of $\mathrm{SC}$, the second variable that significantly determine the performance of SC is the slope. Theoretically, this concept is logical since the accurate slope of SC with average altitude of the sun will increase the intensity of radiation that falls in the SC.

This research still focuses on the verification and confirmation of hypothesis about the innovation in sloped roof solar chimney model. Thus, the hypothesis has been answered and confirmed. For further innovation, future research should develop sloped roof solar chimney with the most optimum slope angle supported with the other component. The development that may be done for innovation towards chimney material is by combining it with (PCM) [3], and the use of perforated absorber plate inside the chimney [12]. A more detail research of the type of inlet construction may also become interesting and significant to be developed [10].

\section{CONCLUSION}

From the result of analysis and the discussion, the conclusions of this research are as follows:

1. There is a unique pattern that indicated the consistence of open space element and solar chimney in the room. The sample point in the middle of the room that is in line with the position of window opening for NSC room has lower temperature than the other rooms. Similarly, the room with roof solar chimney both vertical (VSC) and sloped (SRC), showed increasing contour, that is in contrary with NSC room.

2. There is difference of temperature performance between NSC rooms and SRSC rooms. In addition, there is also significant difference of temperature performance between VRSC and SRSC rooms. The temperature performance of rooms with SRSC is higher than the rooms with VRSC.

3. Geometrical observation towards SRSC leads to the conclusion that the thickness of hollow space in the solarchimney of $50 \mathrm{~cm}$ and $25 \mathrm{~cm}$ with the same inlet height and position is significantly different. However, the difference of inlet height does not cause significant difference on performance.

4. Future research for Indonesia with the warm humid climate and high altitude of sun as well as close to zero latitude needs to focus on the construction details, variation of slope, the use of PCM, and other innovate materials such as absorber component to obtain a more effective performance of solar chimney.

\section{ACKNOWLEDGMENT}

This research is funded by the grant from Ministry of Research, Technology and Higher Education, Republic of Indonesia, Year 2018. The researcher thanks the grant awarder, Universitas Islam Indonesia as the home institution, surveyors, and data processing team. 


\section{REFERENCES}

[1] Sugini and E. Mufida, "Significance of the position and height at performance vertical solar chimney on dense low-cost house in warm humid climate urban," J. Des. Built Environ., vol. 19, no. 3, pp. 24-30, 2019.

[2] D. Zhao, H. Fan, L. Pan, Q. Xu, and X. Zhang, "Energy Consumption Performance

[5] ScienceDirect Experimental and Numerical Studies of Solar Chimney for Ventilation in Low Energy Buildings," Procedia Eng., vol. 205, pp. 1612-1619, 2017.

[6] J. C. DeBlois, M. M. Bilec, and L. A. Schaefer, "Design and zonal building energy modeling of a roof integrated solar chimney," Renew. Energy, vol. 52, pp. 241-250, Apr. 2013.

[7] L. P. Chung, M. H. Ahmad, D. R. Ossen, and M. Hamid, "Effective Solar Chimney Cross Section Ventilation Performance in Malaysia Terraced House," Procedia - Soc. Behav. Sci., vol. 179, pp. 276-289, Apr. 2015.

[8] Y. Lei, Y. Zhang, F. Wang, and X. Wang, "Enhancement of natural ventilation of a novel roof solar chimney with perforated absorber plate for building energy conservation," Appl. Therm. Eng., vol. 107, pp. 653-661, Aug. 2016.

[9] A. Jafari and A. H. Poshtiri, "Passive solar cooling of single-storey buildings by an adsorption chiller system combined with a solar chimney," J. Clean. Prod., vol. 141, pp. 662682, 2017.

[10] M. A. Hosien and S. M. Selim, "Effects of the geometrical and operational parameters and alternative outer cover materials on theperformance of solar chimney used for natural ventilation," Energy Build., vol. 138, pp. 355-367, Mar. 2017.

[11] H. H. Al-Kayiem, K. V. Sreejaya, and A. O. Chikere, "Experimental and numerical analysis of the influence of inlet configuration on the performance of a roof top solar chimney," Energy Build., vol. 159, pp. 89-98, 2018.

[12] A. Abdeen, A. A. Serageldin, M. G. E. Ibrahim, A. El-Zafarany, S. Ookawara, and R. Murata, "Solar chimney optimization for enhancing thermal comfort in Egypt: An experimental and numerical study," Sol. Energy, vol. 180, pp. 524-536, Mar. 2019.

[13] I. Zavala-Guillén et al., "Ventilation potential of an absorber-partitioned air channel solar chimney for diurnal use under Mexican climate conditions," Appl.Therm. Eng., vol. 149, pp. 807-821, 2019.

[14] M. Fathoni and M. A. Kristianto, "Passive Application through Solar Induce Ventilation on Sustainable Building in Equatorial
Considering Climate Change in Office Building," Procedia Eng., vol. 205, pp. 34483455, Jan. 2017.

[3] C. Jiménez-Xamán et al., "Solar chimneys with a phase change material for buildings: An overview using CFD and global energy balance," Energy Build., vol. 186, pp. 384-404, 2019.

[4] X. Zha, J. Zhang, and M. Qin, "ScienceDirect Hemisphere," Procedia Environ. Sci., vol. 20, pp. 126-130, Jan. 2014.

[15] M. Khosravi, F. Fazelpour, and M. A. Rosen, "Improved application of a solar chimneyconcept in a two-story building: An enhanced geometry through a numerical approach," Renew. Energy, vol. 143, pp. 569585, Dec. 2019 
